\section{Research Article}

(C) 2022 Bijani et al. This is an open access article licensed under the Creative Commons Attribution-NonCommercial 4.o International License (https://creativecommons.org/licenses/by-nc/4.o/)

\title{
A Comparative Study of Power Distance of English Teachers and Non- English Teachers in Classroom Interaction in Iranian High Schools
}

\author{
Houman Bijani \\ Ph.D., Assistant Professor in TESOL, \\ Islamic Azad University, \\ Zanjan Branch, Zanjan, Iran; \\ Corresponding Author \\ Somayeh Jamali \\ Ph.D. Candidate, \\ Islamic Azad University, \\ Karaj Branch, Karaj, Iran

\section{Salim Said Bani Orabah} \\ Ed.D., Head of English Language Center, \\ University of Technology \& Applied Sciences, \\ Ibra, Oman
}

DOI: https://doi.org/10.36941/ajis-2022-0046

\section{Abstract}

Since cultural factors play a crucial role in creating behavioral patterns, investigating the relationship between English teachers and students can be a good index for discovering the level of power distance in the classroom environment with different cultures manifesting in their interactions. The current study has attempted to compare female high school students' viewpoints towards English teachers and non-English teachers in the Iran context to discover the difference in power distance between English and non-English teachers and their students. To this end, the present research was conducted in 3 high schools for females with female teachers, and the data was gathered through a five-item Likert scale questionnaire investigating students' viewpoints towards five main elements: Acceptability, Respect, Teaching method, behavioral patterns, and Friendship. The findings revealed a high power distance between English teachers and their students in an English class interaction than non-English teachers such as science teachers, math teachers, physics teachers, chemistry teachers, and art teachers and their students. In turn, the results implied positive viewpoints towards English teachers. Regarding four factors, Acceptability, Respect, Teaching method, and Behavior, there is a significant difference between the viewpoints towards English and non-English teachers. On the other hand, there is no significant difference between the two variables in terms of friendship.

Keywords: English teachers; Non-English teachers; Power distance; Students'viewpoint 


\section{Introduction}

Language can be considered a core part of culture since it is continually affected by cultural factors, and the development of second language acquisition is mainly based on the extent to which the acculturation takes place through a natural setting (Schumann, 1976). Enormous cross-cultural studies are focusing on the role of culture, especially regarding power distance element in language acquisition (Chinh, 2013; Cray, McKay \& Mittelman, 2019; Kasuya, 2008; Ly, 2013; Mokhtarnia, 2011; Prastiwi, 2013; Santilli \& Miller, 2011; Yeganeh \& Raeesia, 2015; Zhang, 2005). Acculturation refers to a phenomenon through which different people with different cultures come together and manifest changes in their original cultural patterns due to exposing a new culture and can affect the members of two or more cultural groups (Ting-Toome \& Dorjee, 2018). In general, students come to class with different cultural backgrounds, bringing a new perspective about the surrounding world and variations in groups like ethnicity, individual characteristics, and learning opportunities. In addition, cultural norms function as an external force to guide behaviors. So, knowing their culture leads us as teachers to manage the class based on shared regularities, values, and norms. It is crucial to understand students' individual and collective culture in an English class since learning occurs through communication and interaction with others. In fact, without having a powerful insight into the target language's culture, it would not be possible to understand the different aspects of language learning since these two elements are interwoven with each other strongly, and the values in language are affected by the values of culture.

On the one hand, as cited in Rod Ellis's (2010) book 'Second Language Acquisition', Schumann refers to culture shock in which EFL/ESL learners feel anxious and disorientated upon entering a new culture. On the other hand, learners are frequently exposed to the learning environment in which there is a power distance between learner and teacher during the interaction. The relationship between teacher and student is considered as a hierarchy displaying power distance in their interactions. Hofstede (1986) focused on cultural borders and the importance of differences in cultural values between nations. He proposed four dimensions of Individualism / Collectivism, Uncertainty Avoidance, Power Distance, and Masculinity / Femininity that take place in interaction. To present effective teaching, it is essential to know the social factors involved during interaction and pay attention to related consequences. According to the relationship between teacher and students in terms of power distance element, we can infer teacher-student interpersonal behavior in which there may be different kinds of problems during communication, especially for inexperienced teachers. So, knowing students' perceptions of teachers' behavior can be crucial to facilitating teaching barriers for the teachers and the learning process for the students (Telli et al., 2007).

Because previous studies do not offer sufficient evidence on the students' visions towards Iranians' English and non-English high school teachers, the current study aims to specify the values of high school teachers by investigating interactions between teachers and students in the classroom environment. The core focus is on the comparison between patterns of behavior of students and their opinions towards English and non-English teachers in the hierarchy of power distance since the obtained result can affect English teachers' decisions about class experiences and problems in an English class and the relationship between teacher and student, and anxiety inherent in an English class due to unfamiliarity of students with a foreign language on the one hand and the power distance existed in all classes on the other hand. Mokhtarnia (2011) believes that the context of Iran possesses a static and structured view towards social identity considering that each individual has a certain stance and social identity as a member of a particular social group. Given this perspective, it can be argued that students can manifest different social identities and behavioral patterns, especially concerning the relationship between English teachers and students due to the effects of the target language culture offered by the teacher. This is in line with what Korte (2007) specifies as the multiple social identities of learners depending on a particular situation and social interaction. On the other hand, Solgi and Tafazoli (2020) assert that in an English class in Iran, there is a monoculture status in which all students come from one common culture and manifest nearly the same cultural norms and values. Therefore, evaluating 
probable differences between students' insights and behavioral patterns in given English and nonEnglish classes towards teachers would be beneficial to discover the motivating effects on the language learning process. Considering this, the main research question is as follows:

RQ: Is there any significant difference between Iranian high school students' perspectives towards English and non-English teachers regarding power distance and behavioral social patterns?

\section{Review of Literature}

The term 'Power Distance' has been defined by some scholars, such as social psychologist Mauk Mulder (1977). He refers to power distance as the range of inequality between I and O belonging to the same social system. Based on Geert Hofstede, power distance refers to the relationship between superior and subordinate in which the subordinate's behavior is affected by the superior and vice versa (Culture's Consequences, 1980, 2001). Hofstede suggested a small power distance index (PDI) to explain national cultures and believed in existential inequality between superiors and subordinates in large power distance. He argued that individuals perform separate mental activities for work and non-work conditions, and all superior work values at a workplace or in society have rooted in the family or school environment.

Moreover, Ly (2013) claims that people's behaviors manifest in different masks wearing in different contexts in society. In addition to that, Ly believes that people are not completely liquid, and their values can be changed through their personal history. Specifically, the power distance in the school environment is considered by scholars since there is some degree of strict order in the teacher-student interaction, in turn, the most of learning process and cooperation in the classroom is affected by this hierarchy (Pavett \& Morris, 1995). Regarding power distance in the classroom, especially English class, many scholars refer to voluntary interaction and communication affected by power distance as a cultural factor influencing language learning. Kasuya (2008) pointed to students' hesitation to speak in front of other students and a teacher in not only English classes but also in other subject classes. There is no sufficient free interaction between teachers and students, and students tend to be passive rather than active individuals. This issue is highlighted especially concerning power distance, either low or high degree. Kasuya reports that power distance affects classroom interaction as a negative factor. In his study, he clarifies these effects and concludes that teachers dominate learners in large power distance societies, while in small power distance societies, free interaction occurs actively. In this regard, there is a serotype e implying that in Asian classrooms, there is high power distance. In most countries like Turkey, Japan, Iran, and China, English teachers use students' family names to address them which imposes more inequality between teachers and students, while this inequality is not considered in the West.

It is believed that the degree of development in learning and teaching is highly influenced by the knowledge of teachers about their students' background and the context in which teachers' behavior in dealing with their students' needs and preferences is based (Piazza, Rao \& Protacio, 2015). Educators have always agreed on setting an environment with more open and flexible students and a climate of free exchange of information and dynamic interaction to promote students' learning and curricular skills and knowledge. However, the hierarchical relationship in the form of authority and subordinate relation starts within the home and progresses along with the school community. Social networks create this mutual relationship which is needed to be considered in the classroom culture. In most countries with high power distance such as Iran, students preserve this distance relationship by applying formal titles like Sir, Mr., Professor, etc. They are very conservative in keeping this hierarchical order and try to have their place through respecting teachers in the class to prevent probable damage in this relationship.

One of the dimensions of Model for Interpersonal Teacher Behavior (MITB) describes Influence (Dominance-Submission) which represents the level of superiority or control demonstrated by teachers in the classroom. Based on Telli et al. (2007), the result of many studies has shown that dominance is perceived more by students rather than submissiveness. Similarly, one study has shown that there are differences between teachers in terms of the degree of influence or proximity in the classroom 
compared to other subjects' teachers, and also the result has suggested that science teachers in the Netherlands are perceived to a lower degree than other countries such as the USA. Moreover, developing a good relationship with students is a core issue in teacher education to improve teachers' moral competency and ethical sensitivity (Gholami et al., 2015). According to Wubbels and Brekelmans (2005), teacher and students' interaction can influence students' achievement and motivation.

Similarly, Nugent (2009) reported that teacher-student relationships are very important to student success. As it was mentioned before, one of the aspects of power distance is related to cultural factors. The low or high power distance dimension of the hierarchy holding in a classroom between teacher and students depends on the culture of each context. Thus, there can be different degrees of the vision of superior-subordinate relationships in different contexts due to cultural diversity. Gholami et al. (2015) believed that teachers' values, norms, and ideology are involved in the negotiation and interaction driven from the moral entity and ethical issue relating to the teaching profession in the context of classroom communities. English language has been taught as a foreign language in Iran, mainly for political, social, economic, and educational reasons rather than a pure academic factor (Farhady et al., 2010). Based on Sabooriet al. (2015), Iranian culture can be explained as a culture of large power distances, collectivism, and femininity with a short-term orientation. Gholami et al. (2015) report that Iran has gained a high score on power distance representing social norms and unequal distribution of power in Iranian society, and the students cannot talk as much as a teacher in the classroom. So, the current study aims at finding the difference between English and non-English teachers' power distance score in Iranian high schools through investigating students' opinions towards them and exploring the degree of power distance element in their relationship.

\section{Method}

The design of the current study is quasi-experimental research aiming at comparing the power distance of English and non-English teachers in classroom interaction in high schools of Iran context. As there is gender separation in Iranian schools, the research was merely conducted in three high schools for females with female students in Tehran to investigate the power distance that existed between English and non-English teachers and their students. The respondents of the study were recruited randomly (through stratified random sampling). Considering the power distance element, the researcher developed a questionnaire based on a five-item Likert scale through piloting 32 questions and evaluating Cronbach's alpha to verify its reliability and validity. The questionnaire consisted of 32 items investigating five main elements with sub-items: Acceptability, Respect, Teaching method, behavioral patterns, and Friendship with the scores 0.84 , 0.70, 0.84 , 0.70 , and o.88 respectively. Three hundred thirty-eight questionnaires were gained out of 500 distributed questionnaires. The items of the questionnaire were related to students' viewpoint towards English and non-English teachers to measure the five elements through 5 scales (Never=1, Occasionally =2, Sometimes=3, Often $=4$, Always $=5$ ). Each respondent was given two questionnaires with the same items and different responses regarding viewpoints towards English teachers and non-English teachers. Table 1 represents the demographic data of the students taking part in this study to indicate their viewpoints about teachers of English and non-English majors. As we can see in the Demographic table, students' age ranges from 15 to 19 studying in different majors.

Table 1: Demographic data of the students taking part in the study

\begin{tabular}{|l|c|c|c|}
\hline Title & frequency & Percentage \\
\hline \multirow{4}{*}{ Age } & 15 & 28 & 7.5 \\
\cline { 2 - 4 } & 16 & 135 & 38.5 \\
\cline { 2 - 4 } & 17 & 155 & 43.4 \\
\cline { 2 - 4 } & 18 & 37 & 10.3 \\
\cline { 2 - 4 } & 19 & 1 & .3 \\
\hline
\end{tabular}




\begin{tabular}{|l|c|c|c|}
\hline \multicolumn{2}{|l|}{ Title } & frequency & Percentage \\
\hline \multirow{4}{*}{ Level } & $1^{\text {th }}$ & 140 & 39.1 \\
\cline { 2 - 4 } & $1^{\text {th }}$ & 133 & 37.2 \\
\cline { 2 - 4 } & $12^{\text {th }}$ & 79 & 22.1 \\
\cline { 2 - 4 } & Others & 6 & 1.7 \\
\cline { 2 - 4 } Major & Mathematic & 94 & 26.3 \\
\cline { 2 - 4 } & Practical science & 160 & 44.7 \\
\cline { 2 - 4 } & Humanities & 56 & 15.6 \\
\cline { 2 - 4 } & Others & 48 & 13.4 \\
\hline
\end{tabular}

\section{Results}

Table 2 displays the mean and standard deviation of students' attitudes and viewpoints towards their English and non-English major teachers. Table 3 also indicates whether there is any significant mean difference between the students' attitudes and viewpoints regarding the aforementioned matter. The results indicate that there is a significant difference between students' viewpoints towards English and non-English teachers with a significant level of 0.99 at the level of 0.01 and also 357 degrees of freedom. The tables also display the mean difference of two questionnaires (7.99), verifying the more positive opinions of students towards English teachers than non-English teachers.

Table 2: The mean and standard deviation of the two groups

\begin{tabular}{|l|l|c|c|c|}
\hline & Group & Mean & Std. Deviation & Std. Error Mean \\
\hline \multirow{2}{*}{ Scores } & English teachers & 124.17 & 17.84 & .94 \\
\cline { 2 - 5 } & Other teachers & 116.18 & 21.89 & 1.15 \\
\hline
\end{tabular}

Table 3: Independent Sample T-test results of two variables

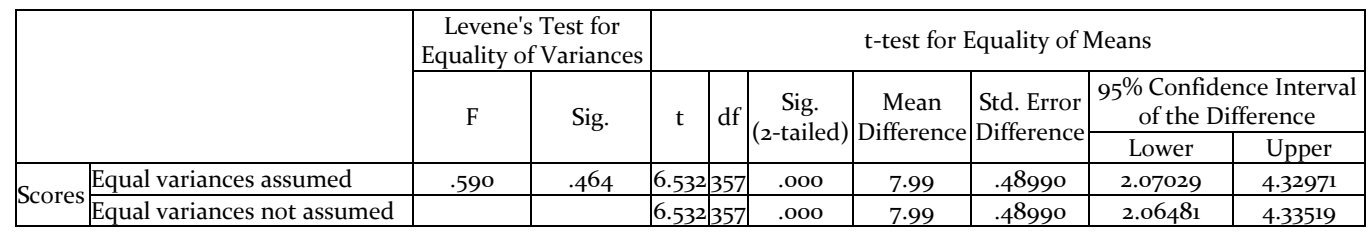

Table 3, which is dedicated to reporting the results of paired sample T-test of five factors affecting the power distance between teachers, either English or non-English, and their students, proves that the analyzed sets of scores reject the null hypothesis. In fact, regarding Acceptability, Respect, Teaching method, and Behavior, there is a significant difference between two variables of the research (viewpoints towards English and non-English teachers) at the level of o.o1 error.

On the other hand, there is no significant difference between the two variables in terms of friendship. As a result, the mean scores obtained from students' viewpoints towards English teachers regarding acceptability, respect, teaching method, and behavior are more than non-English teachers.

Table 4: T-test results of subscales

\begin{tabular}{|l|l|c|c|c|c|c|c|}
\hline & & Mean & $\begin{array}{c}\text { Std. } \\
\text { Deviation }\end{array}$ & $\begin{array}{c}\text { Std. Error } \\
\text { Mean }\end{array}$ & t & df & Sig. \\
\hline Pair 1 & Other.acceptability English.Acceptability & -.95531 & 4.80700 & .25406 & -3.760 & 357 & .000 \\
\hline Pair 2 & Other.Expect English.Expect & 4.09218 & 3.57472 & .18893 & 21.660 & 357 & .000 \\
\hline Pair 3 & other.Teaching method English.Teaching method & -3.35754 & 7.03657 & .37189 & -9.028 & 357 & .000 \\
\hline Pair 4 & Other.Behavior English.Behavior & -3.10335 & 6.32127 & .33409 & -9.289 & 357 & .000 \\
\hline
\end{tabular}




\section{Discussion}

The current study aimed at comparing the power distance of English and non-English teachers in classroom interaction and communication in Iranian high schools. The findings of the study implied the significant difference between students' viewpoints towards English and non-English teachers in terms of power distance in Iranian high schools for females. As a result, the research hypothesis was rejected, and statistical analysis proved that students' viewpoints towards English teachers' power distance are mostly higher than other teachers in their school, such as science teachers, math teachers, physics teachers, chemistry teachers, and art teachers. Based on these results, we can argue that the power distance between English teachers and their students is larger than non-English teachers. Based on Hofstede (2005) culture is considered as programming of mind with the capability of distinguishing the individual of one group from other members. Jaber (2015) claims that Hofstede's cultural framework consisting of five dimensions (power distance, individualism and collectivism, masculinity and femininity, uncertainty avoidance, and long or short orientation) affects values on teacher practices, and in turn students' cultural identity. So, the effects of culture manifest in the educational setting like school with the focus on mutual behaviors and viewpoints among teachers and students. Hofstede (2005) believes that power distance accounts for unequally distributed power between less powerful members of a group or institution and superior members. Nelson (200o) classifies classrooms in terms of low and high power distance occurred in them. He asserts that teachers take responsibility for students' learning in a high power distance and expect students to respect them. Teachers and students tend to call each other more formal. Students are silent most of the time and do not ask many questions when they have problems. Similarly, as mentioned before, in Iran society there is high power distance in educational settings in that the students have to respect their teachers as they also obey their parents and elderly at home. At school, students have to take permission to speak, try not to initiate conversation and communication before their teachers, and most of the time they depend on teachers in a teacher-centered class. In a teacher-centered class, this is the authority of the teacher which specifies the manner of communication and interaction between students as well as student and teacher and it is the teacher responsibility to make a suitable interaction with students especially in a Communicative Language Teaching (CLT) method in high power distance context like Iran.

In language learning and teaching environment, power distance and individualism-collectivism are considered to be the only two main dimensions that are the interest of most researchers in terms of investigating collective manner of learning and teacher-learner relationship (superior and subordinate hierarchy) in a class. Hofstede (2008) asserted that power distance is the main factor in team relationships and accordingly as there is low cooperation and participation in an English class due to inherent reluctance of students to engage in English class's activities, it is more likely to be more challenging situations for students in high power distance contexts and also students' autonomy in decision-making and solving problems decrease because students always prefer to be independent in the class while they are not allowed in a high power distance class (Alshahrani, 2017). This claim is in line with Paulus's et al. (2007) findings revealing that in low power distance context, the members of a project-based team at higher education operated successfully in overcoming potential conflicts due to miscommunication because low power distance is likely facilitated the trust decreasing the burden of difficulties existed in non-native language learners' communication. The degree of power distance in the class affects students' perception of the teacher. So, it is expected to have more power distance in an English class than non-English classes.

Although the results of the study conflict with Dongmei and Guo's (2012) findings concluding non-English power distance tended to be larger than that of English teachers, they believed that language was the only contributing factor that led to valued deviation and power distance range. Regardless of the age aspect, it is better to note that they referred to the age factor in power distance asserting that Hofstede (2008) believed younger teachers are more equal and closer to their students and per se have low power distance in the class compared to older teachers. 


\section{Conclusion}

We find it insightful to conclude by referring to Simmons et al. (2019) that respecting to power distance entity, in different situations such as the relationship between managers and employees as superiors and subordinates, Kuwaiti women perceive low power distance since they tend to have a negative attitude towards other women. So, for the porous of this study, we can conclude that the positive attitude implies more power distance between English teachers and students in classroom interaction, especially among females. This result can be explained in this belief that the increasing need for English language learning for different purposes has led to forming positive opinions towards this lingua franca. This universality of language use can be related to political, social, and economic issues, leading to more positive insights into the English language, especially the factors investigated in this study. In contrast, Dongmei and Xing (2012) have concluded that English teachers' power distance is lower than non-English teachers. Therefore, there should be a varying degree of power distance between superior and subordinate in general and teachers and students in specific in the continuum of relationship and interaction in different cultures. Consequently, it is very essential to consider that what happens to the processes of teaching and learning in the low and high power distance in educational settings and how teachers and students treat when there is a hierarchical relationship with different ranges of authority, autonomy, and creativity of both sides in the class. To have a more valuable vision towards English classes and analyze the learners' needs in a way that they reach the desired autonomy especially in terms of making proper communicative interaction with desired rapport and collaboration with their teacher. It is again very essential to account for all students' points of view in high power distance to give them equal chance to express themselves as there is a risk of ignoring some silent and introverted students in a class where the teacher as an authority of the class pay more attention to extroverted students.

\section{References}

Berry, J. W. (1997). Immigration, acculturation, and adaptation. Applied psychology: An International Review, 46(1), 5-34. doi.org/10.1111/j.1464-0597.1997.tbo1087.x

Chinh, N. D. (2013). Cultural Diversity in English Language Teaching: Learners' Voices. English Language Teaching, 6(4), 1-7. doi:10.5539/elt.v6n4p1

Cray, D., McKay, R., \& Mittelman, R. (2019). Teaching in Iran: Culture and consequences. Intercultural Education, 30(4), 429-444. doi.org/10.1080/14675986.2018.1540109

Dongmei, L. I., \& Xing, G. U. O. (2012). A Comparison of Power Distance of Chinese English Teachers and Chinese Non-English Teachers in Classroom Communication. Intercultural Communication Studies, 21(1). 221-239.

Ellis, R. (2010). Second language acquisition, teacher education, and language pedagogy. Language Teaching, 43(2), 182-201. doi:10.1017/So261444809990139

Farhady, H., Hezaveh, F. S., \& Hedayati, H. (2010). Reflections on Foreign Language Education in Iran. TESL-EJ, 13(4), 1-18.

Gholami, K., Kuusisto, E., \& Tirri, K. (2015). Is ethical sensitivity in teaching culturally bound? Comparing Finnish and Iranian teachers' ethical sensitivity. Journal of Comparative and International Education, 45(6), 886-907. doi.org/10.1080/03057925.2014.984588

Hofstede, G. (1986). Cultural differences in teaching and learning. International Journal of Intercultural Relations, 10(3), 301-320. doi.org/10.1016/0147-1767(86)90015-5

Kasuya, M. (2019). Classroom interaction affected by power distance. Language Teaching Methodology and Classroom Research and Research Methods, 18(1), 1-12.

Korte, R. F. (2007). A review of social identity theory with implications for training and development. Journal of European Industrial Training, 31(3), 166-180.

Ly, A. (2013). A critical discussion of Hofstede's concept of Power Distance. London: International House Inc.

Mokhtarnia, S. (2011). Language education in Iran: A dialogue between cultures or a clash of identities. ProcediaSocial and Behavioral Sciences, 15(4), 1998-2002. doi.org/10.1016/j.sbspro.2011.04.042

Mulder, M. (1977). The daily power game. Leiden, the Netherlands: Martinus Nijhoff. Social Sciences Division. Oxford: UK. 
Nelson, G. A. Y. L. E. (200o). Individualism-collectivism and power distance: Applications for the English as a second language classroom. The CATSOL Journal, 12(1), 73-89.

Nugent, T. (2009). The impact of teacher-student interaction on student motivation and achievement. Retrieved from https://stars.library.ucf.edu/etd/386o

Pavett, C., \& Morris, T. (1995). Management styles within a multinational corporation: A five-country comparative study. Human Relations, 48(10), 1171-1191. doi.org/10.1177/001872679504801004

Piazza, S. V., Rao, S., \& Protacio, M. S. (2015). Converging recommendations for culturally responsive literacy practices: Students with learning disabilities, English language learners, and socioculturally diverse learners. International Journal of Multicultural Education, 17(3), 1-20. doi.org/10.18251/ijme.v17i3.1023

Prastiwi, Y. (2013). Transmitting local cultural knowledge through English as foreign language (EFL) learning as a means of fostering "unity in diversity". Academic Journal of Interdisciplinary Studies, 2(3), 507-513. doi: 10.5901/ajis.2013.v2n3P507

Saboori, F., Pishghadam, R., Hosseini Fatemi, A., \& Ghonsooley, B. (2015). Culture and identity: Linking Iranian identity components and cultural dimensions. Issues in Language Teaching, 4(1), 78-49. 10.22054/ILT.2015.3463

Santilli, V., \& Miller, A. N. (2011). The effects of gender and power distance on nonverbal immediacy in symmetrical and asymmetrical power conditions: A cross-cultural study of classrooms and friendships. Journal of International and Intercultural Communication, 4(1), 3-22. doi:10.1080/17513057.2010.533787

Schumann, J. H. (1976). Social distance as a factor in second language acquisition. Language Learning, 26(1), 135143. doi.org/10.1111/j.1467-1770.1976.tboo265.x

Simmons, A. L., Duffy, J. A., \& Alfraih, H. S. (2019). The influence of social dominance orientation and power distance on attitudes toward women managers. Journal of Behavioral and Applied Management, 19(1), 22-40.

Solgi, F., \& Tafazoli, D. (2020). The necessity of teaching culture in English as a foreign language course: Iranian perspective. Journal of Language and Linguistic Studies, 16(3), 1-11.

Telli, S., Den Brok, P., \& Cakiroglu, J. (2007). Students' perceptions of science teachers' interpersonal behavior in secondary schools: Development of a Turkish version of the Questionnaire on Teacher Interaction. Learning Environments Research, 10(2), 115-129. doi.org/10.1007/s10984-007-9023-2

Ting-Toomey, S., \& Dorjee, T. (2018). Communicating across cultures. London: Guilford Publications.

Woodside, A. G., Hsu, S. Y., \& Marshall, R. (2011). General theory of cultures' consequences on international tourism behavior. Journal of Business Research, 64(8), 785-799.

Wubbels, T., \& Brekelmans, M. (2005). Two decades of research on teacher-student relationships in class. International Journal of Educational Research, 43(1-2), 6-24. doi:10.1016/j.ijer.2006.03.003

Yeganeh, M. T., \& Raeesi, H. (2015). Developing cultural awareness in EFL classrooms at secondary school level in an Iranian Educational context.Procedia-Social and Behavioral Sciences, 19(2), $534-542$. doi.org/10.1016/j.sbspro.2015.06.084

Zhang, Q. (2005). Immediacy, humor, power distance, and classroom communication apprehension in Chinese college classrooms. Communication Quarterly, 53(1), 109-124. doi.org/10.1080/01463370500056150 